\title{
Questão ambiental e pandemia: a destrutividade do sistema do capital na ordem do dia
}

\author{
Gessyca Andrea de Lima Baracho ${ }^{1}$ \\ https://orcid.org/0000-0002-3506-3525 \\ ${ }^{1}$ Universidade Federal de Pernambuco, Departamento de Serviço Social, Programa de Pós-Graduação em Serviço Social, \\ Recife, PE, Brasil
}

\section{Questão ambiental e pandemia: a destrutividade do sistema do capital na ordem do dia}

Resumo: O presente artigo tem como objetivo refletir sobre a relação entre a questão ambiental, crise estrutural do capital e a pandemia do novo Coronavírus. Compreendemos neste trabalho que a pandemia do novo Coronavírus que gera a doença nomeada de Covid-19 está organicamente relacionada com a crise do capital, como fruto do processo de acumulação capitalista avidamente crescente que necessita da exploração inesgotável dos recursos humanos e naturais, tornando-os mercadorias. Essa dupla exploração em ritmo galopante, inerente à ordem sociometabólica do capital, constituem elementos fundamentais para o atual cenário de crise mundial. Para tal reflexão, caminhamos sob a perspectiva do método dialético-crítico de Marx, utilizando-se como metodologia a pesquisa de caráter bibliográfico e documental. Dividimos o trabalho em duas seções centrais: a primeira discute a questão ambiental e a ordem sociometabólica do capital, relação de acumulação e destrutividade; a segunda realiza a relação entre os três eixos de discussão: a crise do capital, a pandemia e a questão ambiental.

Palavras-chave: Questão Ambiental. Pandemia. Capital. Acumulação Capitalista.

Environmental issue and pandemic: the destructiveness of the capitalism system on the agenda of the day

Abstract: This article aims to reflect on the relationship between the environmental issue, structural crisis of capitalism and the new Coronavirus pandemic. We understand in this work that the pandemic of the new Coronavirus that generates the disease named Covid-19 is organically related to the crisis of capitalism, as a result of the accumulation process greedily growing capitalist that needs the inexhaustible exploitation of human resources and natural, making them commodities. This double exploration at a galloping pace, inherent to sociometabolic order of the capital, constitute fundamental elements for the current scenario of world crisis. For such reflection, we walk under the perspective of the dialectical-critical method of Marx, using bibliographic and documentary research as a methodology. We divided the work into two central sections: the first discusses the environmental issue and the order sociometabolic of capitalism, relation of accumulation and destructiveness; the second analyzes the relationship between the three perspectives of the discussion: the crisis of capitalism, the pandemic and the environmental issue.

Keywords: Environmental Issue. Pandemic. Capital. Capitalist accumulation.

Recebido em 24.02.2021. Aprovado em 15.05.2021. Revisado em 07.07.2021.

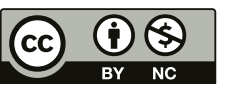

Este é um artigo publicado em acesso aberto (Open Access) sob a licença Creative Commons Attribution NonCommercial, que permite uso, distribuição e reprodução em qualquer meio, sem restrições desde que sem fins comerciais e que o trabalho original seja corretamente citado. 


\section{Introdução}

Ao longo das últimas décadas o agravamento da questão ambiental vem se tornando imperativa a sua discussão. Mas é importante tornar evidente no debate crítico que a problemática ambiental está estruturalmente vinculada ao modo de produção capitalista, como consequência inerente da dinâmica da acumulação, e não como um evento pontual que pode ser administrado sob a perspectiva do capital (SILVA, 2010). Esse modo de produção que tem por finalidade fundamental a formação de excedente para obtenção de lucros tem por base a crescente exploração dos recursos da natureza e da força de trabalho humana, os quais se tornam mercadorias para atingir esse fim. Essa dinâmica de exploração e acumulação capitalista cada vez mais se eleva e se amplia e seus efeitos destruidores se fazem sentir, e a atual pandemia do novo Coronavírus constitui expressão desse processo.

A pandemia do novo Coronavírus, Sars-CoV-2, que gera a doença nomeada de Covid-19, surge no Mercado Atacadista de Wuhan, na China, no início do primeiro semestre de 2020, mas com pouco tempo depois se dissemina pelos países do mundo. Momentos de desespero e medo pelo avanço de uma doença desconhecida e altamente contagiosa, que achávamos que se resolveria em poucos dias, arrastou-se por longos meses. A economia mundial estagnou, a princípio, o desemprego aumentou, a quarentena se instaurou e a morte de muitos também foi e ainda continua sendo noticiada pelas grandes mídias.

Desse modo, a atual pandemia tem anunciado a face destrutiva do sistema do capital de forma ainda mais assustadora, revelando as contradições inerentes a um sistema que tem no lucro o seu fim último, e que as consequências desse objetivo seja a própria devastação. A pandemia demonstrou a insustentabilidade da sociedade do capital, acirrando o cenário de crise do capital, a qual tem na degradação ambiental as suas raízes. Essa degradação socioambiental é resultado das relações sociais vigentes, mediadas pela via do mercado. Dito isto, defendemos que o vírus não é a crise, o sistema capitalista é a própria crise (GOUVÊA, 2020; MASCARO, 2020).

Nesse sentido, o presente artigo teve como objetivo refletir sobre a relação da questão ambiental, crise estrutural do capital e a pandemia do novo Coronavírus, afirmando que ela está organicamente relacionada com a crise do capital, como fruto do processo de acumulação capitalista avidamente crescente que necessita da exploração inesgotável dos recursos humanos e naturais, tornando-os mercadorias. Essa dupla exploração em ritmo sempre crescente, inerente à ordem sociometabólica do capital (MÉSZÁROS, 2015), constituem elementos fundamentais para o atual cenário de crise mundial.

Para tal reflexão, caminhamos sob a perspectiva do método dialético-crítico de Marx, utilizando-se como metodologia a pesquisa de caráter bibliográfico e documental. Dividimos o trabalho em duas seções centrais: a primeira discute a questão ambiental e a ordem sociometabólica do capital, relação de acumulação e destrutividade; a segunda realiza a relação entre os três eixos de discussão: a crise do capital, a pandemia e a questão ambiental.

\section{A questão ambiental e a ordem sociometabólica do capital: acumulação e destrutividade}

No capitalismo contemporâneo, os processos de destruição da natureza têm cada vez mais se tornado uma realidade em ascensão. $\mathrm{O}$ avanço da degradação ambiental em níveis alarmantes é uma tendência mundial, mesmo que seus efeitos se façam sentir de modos distintos entre os países de capitalismo central e periféricos ${ }^{1}$, e estes, em especial, de modo ainda mais avassalador. Esse avanço está intimamente relacionado ao processo de acumulação capitalista, uma vez que para o capital se reproduzir e se expandir continuamente necessita de uma dupla exploração: a força de trabalho humana e os recursos que o ambiente natural dispõe, tornando-os mercadoria.

De acordo com Silva (2010), as manifestações desse processo de destruição da natureza se encontram na escassez dos recursos naturais, nos níveis de aquecimento global, nos efeitos dos poluentes e na produção exacerbada de mercadorias descartáveis, demonstrando que o sistema do capital não tem domínio adequado sobre a natureza, "revelando uma contradição crescente entre as necessidades de expansão da produção e as condições do planeta para promover esse desenvolvimento" (SILVA, 2010, p. 45). 
Essa contradição crescente e fundamental de que aponta a autora entre as necessidades de expansão da produção e as condições do planeta em subsidiar tal desenvolvimento revela a dinâmica do modo de produção capitalista, que para reprodução e acumulação de capital este necessita se tornar mercadoria e, ao fazê-lo, precisa explorar exponencialmente a força de trabalho e os bens naturais. Como esclarece Marx (2011), o capital, como dinheiro, existe como valor, mas para se valorizar, se multiplicar, precisa se transformar em mercadoria e, depois, para retornar seu status de valor, torna-se dinheiro novamente. Esse processo se dá através da circulação.

No processo de produção, a valorização do capital aparece dependente inteira e exclusivamente de sua relação como trabalho objetivado com o trabalho assalariado. Agora, como produto, como mercadoria, aparece dependente da circulação (MARX, 2011). O capital enquanto mercadoria, de acordo com o autor, tem de ser valor de uso, objeto de necessidade, de consumo, mas também tem de ser trocado por seu equivalente em dinheiro (somente na venda o novo valor pode se realizar), ressaltando que a mercadoria só é valor de troca na medida em que é valor de uso, objeto de consumo. A circulação, portanto, é condição necessária para a expansão do capital (MARX, 2011).

A circulação como condição necessária para a busca do valor excedente relativo ${ }^{2}$ cria novas necessidades de consumo, novos valores de uso. Nesse sentido, tem-se a necessidade da formação do mercado mundial. Conforme Marx (2011, p. 540):

A tendência de criar o mercado mundial está imediatamente dada no próprio conceito do capital. De início, o capital tem a tendência de submeter cada momento da própria produção à troca, e de abolir a produção de valores de uso imediatos que não entram na troca, i.e., justamente a tendência de pôr a produção baseada no capital no lugar de modos de produção anteriores, dos seus pontos de vista, espontâneas e naturais. O comércio não aparece mais aqui como uma função operando entre as produções autônomas para a troca do excedente, mas como pressuposto e momento universais da própria produção.

$\mathrm{O}$ autor explica que, de forma natural e inerente, a produção voltada ao uso imediato "reduz tanto o número dos trocadores quanto a soma dos valores de troca que são lançados na circulação e, sobretudo, a produção de valores excedentes" (MARX, 2011, p. 540). Ou seja, a produção capitalista tem como interesse fundamental o valor de troca das mercadorias, uma vez que é por meio da troca de mercadorias que o valor do excedente (mais valor) pode ser extraído. Dessa maneira, diferentemente de modos de produção anteriores ${ }^{3}$, o modo de produção burguês, que tem como essência a concentração de riquezas, altera de forma radical as relações entre sociedade e natureza, "ao adotar como objetivo da produção a formação de excedentes para o mercado com fins de obter lucro [...]" (SILVA, 2010, p. 52).

Com esse objetivo, Marx (2011) aponta que a tendência do capital é ampliar de forma contínua a periferia da circulação e transformá-la em todos os pontos em produção executados pelo capital. Desse modo,

a produção de valor excedente fundada no aumento e no desenvolvimento das forças produtivas, requer a produção de novo consumo; requer que o círculo de consumo no interior da circulação se amplie tanto quanto antes se ampliou o círculo produtivo. Primeiro, ampliação quantitativa do consumo existente; segundo, criação de novas necessidades pela propagação das existentes em um círculo amplo; terceiro, produção de novas necessidades e descoberta e criação de novos valores de uso. (MARX, 2011, p. 540).

Esse processo de acumulação propiciada pela produção de valor excedente decorre da necessária "exploração de toda a natureza para descobrir novas propriedades úteis das coisas; troca universal dos produtos de todos os climas e países estrangeiros; novas preparações (artificiais) dos objetos naturais, como o que lhes são conferidos novos valores de uso". (MARX, 2011, p. 541).

Nessa esteira, a produção baseada no capital tem como condição fundamental a completa exploração da terra para descoberta de novos objetos úteis, de novas propriedades utilizáveis dos objetos existentes, assim como da descoberta de novas propriedades como matérias-primas, "daí o máximo de desenvolvimento das ciências naturais; similarmente, a descoberta, a criação e satisfação de novas necessidades surgidas da própria sociedade; o cultivo de todas as qualidades do ser humano social e sua produção como um ser, o mais rico possível em necessidades [...]" (MARX, 2011, p. 540). Com isso, Marx desvela o movimento real que orienta o modo de produção capitalista, fundado na busca incessante por lucros, que transforma os bens coletivos 
e os sujeitos em mercadoria para sua reprodução; o capital para se reproduzir necessita criar sempre novas necessidades de consumo concomitantemente à necessidade de exploração da força de trabalho.

Desse modo, afirma Marx que, "da mesma maneira que a produção baseada no capital cria, por um lado, a indústria universal - isto é, trabalho excedente, trabalho criador de valor -, cria também, por outro lado, um sistema da exploração universal das qualidades naturais e humanas [...]" (MARX, 2011, p. 542). O autor deixa evidente que ao mesmo tempo em que há a possibilidade de criação de excedente, este acontece como fruto da exploração da força de trabalho humana e dos recursos da natureza. Dessa maneira, "é só o capital que cria a sociedade burguesa e a apropriação universal da natureza, bem como da própria conexão social pelos membros da sociedade" (MARX, 2011, p. 542).

A natureza, para o capital, torna-se puro objeto de consumo ou meio de produção, apropriando-se de forma privada dos recursos naturais, bem como dos produtos do trabalho. O sistema capitalista ao mercantilizar os bens naturais coletivos e alienar os sujeitos das condições materiais de sua existência, criou uma ruptura entre a sociedade e a natureza, o que Foster (2005), apropriando-se do conceito de metabolismo social de Marx, chamou de falha na relação metabólica. Essa ruptura expressa o processo de alienação entre o homem e o meio natural, já que a relação que se constitui orgânica ${ }^{4}$ entre sujeito e natureza passa a ser mediado pela produção de mercadorias, o que configura "um dos traços mais destrutivos da sociedade do capital" (SILVA, 2011, p. 58).

Essa tendência predatória e destrutiva do capital, como afirma Silva (2010), compõe a sua própria natureza, como uma contradição inerente à sua lógica.

[...] ao subordinar a produção aos imperativos da acumulação, o capitalismo não pode sustentar-se indefinidamente, sem que os avanços tecnológicos e científicos por este obtidos resultem em crescente perdularidade e destruição. $\mathrm{O}$ assombroso aumento da produção do capital o faz senhor e voraz devorador dos recursos humanos e materiais do planeta para em seguida, retorná-los como mercadorias de consumo de massa, cada vez mais subutilizados ou, diretamente, como armamentos com imenso poder destrutivo (SILVA, 2010, p. 47).

Ainda segundo Silva (2010), o desenvolvimento das forças produtivas ${ }^{5}$ e avanços tecnológicos para domínio da natureza, promovido pelo modo de produção capitalista, tem-se tornado fonte de destruição, uma vez que estando a serviço dos anseios de acumulação do capital exploram de forma intensiva os recursos naturais, causando sua dilapidação. Desse modo, a ciência e a tecnologia que pretendiam servir aos interesses da coletividade para a melhoria da qualidade de vida dos sujeitos estão, verdadeiramente, submetidas à necessidade de maximização dos lucros (MÉSZÁROS, 2011).

Nesse sentido, Silva (2010, p. 58) afirma que o agravamento dessa tendência tem sua data marcada com o surgimento da grande indústria, posto que "à medida que expressou uma revolução nos meios de produção, aprofundou a "ruptura metabólica", ou seja, a alienação entre os seres humanos e o meio ambiente. A autora continua afirmando que a separação profunda que existe entre a agricultura e a indústria é um dos fatores mais significativos dessa "ruptura metabólica" entre o homem e a natureza.

\begin{abstract}
A indústria de larga escala e a agricultura sob as bases industriais fecham um circuito de depredação da natureza e de exploração do trabalho. Se a indústria se esmera em consumir matérias-primas - portanto, fragmentos da natureza - devolve a esta os resíduos de sua produção em forma de poluentes diversos), ao mesmo tempo em que dilapida o poder do trabalho; por sua vez, enquanto a agricultura retira a força natural do solo, debilita os trabalhadores. Assim, a indústria e o comércio fornecem os meios para a agricultura exaurir o solo [...]. (SILVA, 2010, p. 58).
\end{abstract}

Por consequência, o sistema do capital tem se deparado com a finitude dos recursos naturais e a reduzida capacidade da natureza de absorver sua expropriação elevada com vistas ao lucro e, contraditoriamente, continua tendo a necessidade de expansão da produção e da sua própria autorreprodução. Esses processos configuram a chamada questão ambiental ${ }^{6}$ (SILVA, 2010).

A destrutividade ambiental e social do modo de produção capitalista, portanto, é uma contradição fundamental à medida que a produtividade tem como fim último a concentração e acumulação do capital e não $\mathrm{o}$ atendimento às necessidades humanas. Nesse sentido, com tamanho desenvolvimento tecnológico que hoje 
se apresenta para o aumento expressivo da produção, a exemplo de alimentos em larga escala, como a fome é um fenômeno mundial que ainda persiste? E como essa mesma produção de alimentos tem representado uma verdadeira degradação socioambiental? Acerca disso, Harvey (2011, p. 152) denuncia:

Embora a revolução verde tenha aumentado a produtividade e seja creditada com prevenção da fome em massa, só o fez com todo tipo de consequências negativas em nível ambiental e social. As vulnerabilidades da monocultura significaram investimentos pesados em fertilizantes e pesticidas à base de petróleo (lucrativamente produzidas por empresas estadunidenses, como a Monsanto), e o tipo de capital envolvido (em geral relacionado à gestão de recursos hídricos e à irrigação) implicou a consolidação de uma classe de produtores ricos (com frequência com a ajuda de instituições de crédito duvidosas) e a redução de todos os outros ao status de camponês sem-terra.

São questões como essas que revelam as contradições estruturais inerentes a esse modo de produção que, para angariar legitimação social, se forja no discurso do desenvolvimento. E nos perguntamos: qual tipo de desenvolvimento? O desenvolvimento que tem por base a expropriação dos povos tradicionais de seus territórios para o agribusiness, como acompanhamos o caso da realidade brasileira? A devastação das florestas em busca de minérios para a apropriação privada e enriquecimento de poucos? A superexploração da força de trabalho e dos recursos naturais, esgotando-os? É esse desenvolvimento em nome da acumulação ampliada do capital que tem, progressivamente, alargado as desigualdades sociais e colocado em xeque o futuro da humanidade, e, em especial, daqueles que vivem da força de trabalho.

\section{Crise do capital e pandemia do novo Coronavírus: qual a relação com a questão ambiental?}

Partimos da compreensão neste trabalho de que a questão ambiental está relacionada intrinsecamente com a questão social, posto que esta última se funda na contradição entre capital e trabalho, no processo de exploração e dominação capitalista. A questão ambiental compreendida aqui não está apartada das dimensões sociais, econômicas, políticas e culturais, ou seja, das relações sociais (e de produção) capitalistas, ela se forja nessas relações e se constitui como resultado da intensificação da exploração da força de trabalho humana e dos bens coletivos da sociedade para atender aos interesses da acumulação do capital.

É por isso que a crise do atual cenário mundial evidenciado pela pandemia do novo Coronavírus "tratase de uma crise eminentemente social e histórica" (MASCARO, 2020, p. 5); é a crise do sistema capitalista. Sobre isso, o autor marxista Mascaro (2020, p. 5) é bastante objetivo em sua análise ao afirmar que

[...] a dinâmica da crise evidenciada pela pandemia é do modelo de relação social, baseado na apreensão dos meios de produção pelas mãos de alguns e pela exclusão automática da maioria dos seres humanos das condições de sustentar materialmente sua existência, sustento que as classes desprovidas de capital são coagidas a obter mediante estratégias de venda de sua força de trabalho. O modo de produção capitalista é a crise.

A pandemia do novo Coronavírus, SARS-CoV-2, que gera a doença chamada de Covid-19, surge no Mercado Atacadista de Frutos do Mar de Wuhan, na China, onde são comercializados centenas de espécies de animais, muitos deles ainda vivos, em condições insalubres, como morcegos, cobras e raposas. O surgimento da doença em decorrência do novo vírus ocorreu por um processo chamado de zoonose, processo este que também deu origem a outras várias doenças. Esse processo significa um tipo de transbordamento de vírus ou micróbios de um hospedeiro para outro (LAYRARGUES, 2020). De acordo com o professor, "zoonoses são doenças que antes eram exclusivas de animais não humanos, que por causa do transbordamento, acabaram se tornando também humanas. As zoonoses representam nada menos que cerca de $60 \%$ das doenças infecciosas em humanos". (LAYRARGUES, 2020, p. 8).

Segundo o autor, são diversas as doenças já conhecidas mundo afora que surgem através desse processo de transbordamento, são elas: o vírus da febre amarela, originário de macacos, a Gripe Suína, H1N1, proveniente de porcos, o HIV-1, procedente de chimpanzés, o Sarampo, que provavelmente surge das cabras, entre outras, assim como o novo Coronavírus, que originou a Covid-19, é proveniente de morcegos e, também, do Pangolim (LAYRARGUES, 2020). 
Diferentemente dos discursos conspiratórios sobre o surgimento da Covid-19 (PLITT, 2020), lançando a possibilidade de criação do vírus por meio de laboratórios, na verdade, a pandemia se apresenta como resultado de um desequilíbrio ecológico, como alerta Layrargues (2020), usando como exemplo o surto do Ebola, no ano de 2013, e a gripe aviária.

O surto de Ebola de 2013 na África Ocidental é resultado de significativas perdas florestais devido à agricultura industrial que levou a vida selvagem a circular por fragmentos florestais empobrecidos e então se aproximar dos assentamentos humanos; a gripe aviária está relacionada à criação intensiva de aves e o vírus Nipah por exemplo, surgiu devido à intensificação da suinocultura e à produção de frutas na Malásia, tendo como denotação do surto, incêndios florestais em massa (LAYRARGUES, 2020, p. 8).

O professor atenta que o problema não são os animais silvestres, mas sim o processo de expansão da atividade agropecuária que tem cada vez mais invadido seu habitat. Mas não só isso, no caso da referenciada pandemia, há uma relação direta com a "expansão do consumo de produtos de origem animal selvagem crua ou malcozida de zonas periurbanas, onde existem mercados populares que misturam para comercialização animais domésticos e silvestres vivos em péssimas condições de salubridade (LAYRARGUES, 2020, p. 8), configurando-se como um vetor de zoonoses. Ainda segundo o autor,

O mercado de Wuhan, epicentro do surgimento do Coronavírus, se caracteriza exatamente por esses fatores, onde o morcego e o pangolim (personagens principais desse drama sanitário, entre outros animais amontoados como mercadorias vivas sob forte estresse), ocupam promiscuamente o mesmo espaço com o ser humano. Essa é a conjuntura ideal do transbordamento de um vírus (LAYRARGUES, 2020, p. 9).

Atualmente existe um comércio ilegal em diversos países de carnes de animais silvestres, no qual corresponde por uma "busca gourmet de sabores exóticos" (LAYRARGUES, 2020, p. 9). O pangolim, por exemplo, é um dos animais mais caçados do mundo, "[...] cujo consumo é proibido na União Europeia, pode ser encontrado ilegalmente em alguns restaurantes franceses" (LAYRARGUES, 2020, p. 9). Esse cenário revela como o capital tudo transforma em mercadoria, criando sempre novas necessidades de consumo, expandindo os horizontes da acumulação.

Diante disso, Layrargues (2020) afirma que afora o crescimento do consumo de animais silvestres, em se tratando das epidemias recentes, a raiz do problema está na própria degradação ambiental em dimensões amplas. Conforme o autor:

A qualidade ambiental severamente comprometida está no DNA de origem das epidemias. Onde surgiu o foco inicial das últimas epidemias, foi justamente onde áreas naturais sofreram forte desequilíbrio ecológico, combinando com o aumento da proximidade de rebanhos domésticos com animais selvagens vitimados por seus habitats invadidos e devastados frente à expansão agropecuária. O empobrecimento da biodiversidade como consequência do desmatamento de florestas nativas, causado pelo avanço predatório da fronteira agropecuária, acarreta a debilitação da saúde dos animais silvestres que passam a sobreviver sob severas pressões ambientais (LAYRARGUES, 2020, p. 9).

A intensificação da degradação socioambiental é resultado desse modelo produtivista e consumista do sistema capitalista, ávido, permanentemente, pela obtenção de lucros, o qual subjuga a tudo e todos a este fim, revelando as contradições irremediáveis da ordem sociometabólica do capital (MÉSZÁROS, 2015). Essas contradições revelam os limites absolutos irreparáveis do sistema do capital, que estão no próprio modo de ser do capital, ativados "através da crise estrutural do sistema geral" (MÉSZÁROS, 2015, p. 21).

Dentro desse contexto, Gouvêa (2020) evidencia que a presente pandemia tem sua expressão relacionada organicamente com a expansão do sistema capitalista. A economista revela que

O próprio contato do SARS-CoV-2 com seres humanxs está imbricado na contradição entre desenvolvimento das forças produtivas e relações sociais de produção. É bastante provável que a expansão territorial do capitalismo tenha levado ao contato com vírus presentes em outras espécies e com os quais não teria havido contato em outras circunstâncias. Há então que compreender a expansão do capitalismo na China. O avanço da predominância da mercantilização da reprodução da vida sempre tem por base a expropriação 
primária e secundária da classe trabalhadora. Diga-se, a expropriação das populações camponesas nos países anteriormente socialistas e nos países dependentes - foram e são importantes motores da acumulação capitalista no último período, ao qual denominamos de "neoliberalismo".

Esta relação destrutiva, patriarcal, desenvolvimentista e eurocêntrica que temos com a natureza é especificamente capitalista. Está historicamente determinada, não é 'essencialmente humana'. E pode levar à destruição da maior parte da natureza que hoje conhecemos e inclusive da própria espécie humana. (GOUVÊA, 2020, p. 22).

As expropriações de que se refere a autora são os processos pelos quais os meios de vida, de subsistência dos trabalhadores e trabalhadoras, são transformados em capital. As expropriações primárias significam as expropriações em um momento pré-capitalista, as quais Marx, no capítulo 24 do Capital, chama de Acumulação Primitiva. É o momento histórico do capitalismo em construção onde os camponeses são expropriados de suas terras e dos seus meios de trabalho, tornando-os propriedade privada. Os camponeses, nesse momento, se tornaram homens livres, força de trabalho livre para exploração capitalista (MARX, 2013). Segundo Fontes (2018, p. 31), “Os meios sociais de subsistência, ou dos meios de vida, as condições através das quais os seres sociais asseguravam sua existência, são transformados no processo de expropriação em meios de exploração do trabalho pelo capital". Esse processo violento e sanguinário da história constituiu as bases do modo de produção capitalista. No entanto, esses processos de expropriações continuam a passos largos na contemporaneidade. Já as expropriações secundárias, de acordo com Fontes (2018), são os processos de destruição de direitos, dos bens e serviço públicos, por meio da apropriação do fundo público pelo capital financeiro/rentista como expressão da dinâmica de funcionamento do capitalismo contemporâneo, no processo de produção e valorização do capital, que se aprofundam ainda mais em tempos de crise estrutural do capital.

Esse processo de expansão capitalista inerentemente destrutiva ocorre sob a solidária atuação do Estado em favor do capital. Acerca disso, Harvey (2011, p. 154) aponta:

Os capitalistas e seus agentes se envolveram na produção de uma segunda natureza, a produção ativa de sua geografia, da mesma maneira como produzem todo o resto: como empreendimento especulativo, muitas vezes com a conveniência e a cumplicidade, se não ativa colaboração, do aparelho do Estado.

Nesse sentido, o Estado capitalista cumpre uma função importante no processo de produção e reprodução do capital, posto que “[...] sua composição na base material antagônica do capital não pode fazer outra coisa senão proteger a ordem sociometabólica do capital estabelecida, defendê-la a todo custo, independentemente dos perigos para o futuro da sobrevivência da humanidade" (MÉSZÁROS, 2015, p. 32).

Portanto, o caráter predatório do sistema do capital se dá nas mais diversas esferas da vida social, combinando, no capitalismo contemporâneo, exploração da força de trabalho e espoliação dos recursos materiais e sociais (terra, água, direitos sociais, trabalhistas, e os meios de existência das classes trabalhadoras) (HARVEY, 2004 apud MOTTA, 2018). Dessa forma, essa dupla exploração e a consequente degradação socioambiental vêm se intensificando de forma avassaladora, principalmente nos países de capitalismo periférico, como se destaca o Brasil, no qual temos acompanhado as fraturas expostas do processo crescente de desmatamento e queimadas das florestas da Amazônia ${ }^{7}$ pelo agronegócio, com o aval do Estado, que, possivelmente, em um futuro não tão distante, poderá contribuir para o surgimento de uma próxima pandemia mundial (LAYRARGUES, 2020).

\section{Considerações finais}

Diante de todo o exposto, o presente trabalho teve como objetivo iniciar uma reflexão sobre a relação entre a questão ambiental, crise do capital e pandemia do novo Coronavírus. A pandemia do novo Coronavírus, Sars-CoV-2, que deu origem à Covid-19 e reconfigurou as relações estabelecidas em tempo de normalidade capitalista, levando milhares de pessoas no mundo todo à morte, em especial, as das classes trabalhadoras e subalternas, e outros milhares a sequelas leves e graves, tem seu fundamento no modo como esta sociabilidade vem se organizando. 
A crise gerada pela pandemia se funda neste modelo destrutivo de vida, no modo de produção capitalista, posto que, como defende o professor Mascaro (2020): a crise é o capitalismo. Este é, em essência, socioambientalmente devastador, à medida que tem como objetivo cerne a crescente obtenção de lucros, alcançado pela intensa exploração da força de trabalho humana e dos recursos naturais, tornando-os mercadorias. É diante do agravamento dessas relações que o recado está colocado pela pandemia atual: o sistema do capital é inerentemente insustentável. Nesse sentido, Mészáros (2015, p. 111) afirma de forma esclarecedora que "[...] a dominação e a destruição em curso da natureza devem tornar palpavelmente claro que há um limite para tudo. E os limites absolutos do capital demonstram sua insustentabilidade em nosso tempo não somente em relação a essa questão, mas em diversos outros pontos".

Dessa maneira, os anseios de acumulação ampliada do capital têm aprofundado, cada vez mais, as contradições deste sistema, na qual a pandemia as revelou de forma ainda mais esmagadora. No entanto, aos conhecedores/as do caráter devastador e destrutivo do sistema do capital esse cenário já se constituía como uma ameaça iminente, dada a dinâmica crescente de devastação motivada pelo lucro. Dito isto, precisamos refletir: o que queremos para o futuro pós-pandemia? A perpetuação desse modo de produção explorador, desumanizador e opressor? Ou outra forma de sociabilidade em que o lucro não esteja acima da vida? Defendemos, aqui, a luta pela transformação radical dessa sociedade que tem por base a exploração humana e dos bens naturais. Defendemos a construção de uma outra sociabilidade, de uma sociedade socialista e/ou comunista, em que a socialização dos recursos naturais e sociais sejam direitos fundamentais e não mercadorias, assim como uma sociedade em que seja possível alcançarmos a emancipação humana de todos e todas, colocando fim nos processos de exploração, opressão e dominação a que estão submetidas as classes trabalhadoras e subalternas.

\section{Referências}

AMAZONAS registra aumento histórico de queimadas: Bolsonaro diz que Brasil é o país que mais preserva. Carta Capital, São Paulo, 5 de set. de 2020. Sustentabilidade. Disponível:https://www.cartacapital.com.br/sustentabilidade/amazonas-registra-aumento- historicode-queimadas-bolsonaro-diz-que-brasil-e-o-pais-que-mais-preserva/. Acesso em: 16 jan. 2021.

CAETANO, B. Campeões de desmatamento e queimadas na Amazônia são dominados pelo gado e pela soja. Brasil de Fato, São Paulo, 30 set. de 2019. Disponível em: https://www.brasildefato.com.br/especiais/campeoes-de-desmatamento-e-queimadas-na-amazoniasao-dominados-pelo-gado-e-pela-soja. Acesso em: 15 dez. 2020.

FONTES, V. A transformação dos meios de existência em capital: expropriação, mercado e propriedade. In: BOSCHETTI, I. (org.). Expropriação e direitos no capitalismo. São Paulo: Cortez, 2018. p. 17-62.

FOSTER, J. B. A ecologia de Marx: materialismo e natureza. Rio de Janeiro: Civilização Brasileira, 2005. p. 199-247.

GOUVÊA, M. M. A culpa da crise não é do vírus. In: MOREIRA, E. et al. (org.). Em tempos de pandemia: propostas para a defesa da vida e de direitos sociais. Escola de Serviço Social UFRJ: Rio de Janeiro, 2020. p. 19-28. Disponível em: http://ess.ufrj.br/index.php/ es-es/2-uncategorised/315-em-tempos-de-pandemia-propostas-para-a-defesa-da-vida-e-de-direitos-sociais. Acesso em: 8 dez 2020.

HARVEY, D. O enigma do capital e as crises do capitalismo. São Paulo: Boitempo, 2011.

LAYRARGUES, P. P. Pandemias, colapso climático, antiecologismo: educação ambiental entre as emergências de um ecocídio apocalíptico. Revbea, São Paulo, v. 15, n. 4, p. 1-30, 2020.

MARX, K. Grundrisse: manuscritos econômicos de 1857-1858. Esboços da crítica da economia política. São Paulo: Boitempo, 2011.

MARX, K. O capital: Livro I. São Paulo: Boitempo, 2013.

MASCARO, A. L. Crise e pandemia. São Paulo: Boitempo, 2020.

MÉSZÁROS, I. A crise estrutural do capital: a crise estrutural do capital. 2. ed. São Paulo: Boitempo, 2011.

MÉSZÁROS, I. A montanha que devemos conquistar. 1. ed. São Paulo: Boitempo, 2015.

MOTTA, A. E. Expropriações contemporâneas: hipóteses e reflexões. In: BOSCHETTI, I. (org.). Expropriação e direitos no capitalismo. São Paulo: Cortez, 2018. p. 17-62.

NUNES, L. S. A Questão socioambiental e os Desafios ao Serviço Social. O Social em Questão, Rio de Janeiro, ano XXI, n. 40, p. 209228, jan./abr. 2018. Disponível em: http://osocialemquestao.ser.puc-rio.br/media/OSQ_40_art_9_Nunes.pdf. Acesso em: 6 jan. 2021. PAULO NETTO, J. P.; BRAZ, M. Economia Política: uma introdução crítica. 8. ed. São Paulo: Cortez, 2012.

PLITT, L. Pandemia de covid: por que há tantas teorias da conspiração sobre o coronavírus? BBC News, Brasil, 3 nov. 2020. Disponível em: https://www.bbc.com/portuguese/internacional-54787746. Acesso em 15 maio 2021. 
SILVA, M. das G. Questão ambiental e desenvolvimento sustentável: um desafio ético-político ao Serviço Social. 1. ed. São Paulo: Cortez Editora, 2010.

\section{Notas}

1 Segundo Nunes (2018, p. 212), “No quadro da divisão internacional do trabalho, colonizados ou não, esses países periféricos foram/ são fornecedores de recursos naturais para os países desenvolvidos, sendo constantemente saqueados no processo de expansão capitalista".

2 Marx utiliza de muitos conceitos para explicar o processo de acumulação capitalista. De modo objetivo, Paulo Netto e Braz (2012) explicam que a finalidade do capitalista é sempre o lucro, ou seja, o capitalista compra para vender, uma vez que tem por finalidade nessa relação de compra e venda de mercadorias obter mais dinheiro. A fórmula $D-M$ - $D$ ' significa o movimento do capital que, a partir do dinheiro, produz mercadorias para conseguir mais dinheiro. Os autores explicam que o que importa para o capitalista é o tempo de trabalho excedente, posto que é nessa parte da jornada que se produz o excedente de que o capitalista irá se apropriar. Nesse sentido, "um modo de ampliar o tempo de trabalho excedente consiste na extensão da jornada de trabalho sem alteração do salário" (PAULO NETTO; BRAZ, 2012, p. 121). Se mantém o tempo de trabalho necessário e se acrescenta o tempo de trabalho excedente. Esse modo de produção do excedente se configura como produção de mais-valia absoluta. Uma outra forma de se incrementar o excedente a ser apropriado pelo capitalista, é através da redução do tempo de trabalho necessário à produção (e aumento de tempo de trabalho excedente), por meio da introdução de novas tecnologias e melhor aproveitamento das conquistas científicas. Nesse processo, tem-se a produção de mais-valia relativa.

3 De acordo com Silva (2010), os níveis de destruição ambiental nas sociedades que antecederam o capitalismo não chegaram a representar uma ameaça à sustentabilidade do planeta, uma vez que o objetivo fundamental da produção não era a formação de excedente com vistas ao mercado, e, por consequência, à conquista de lucros. A autora destaca que o baixo desenvolvimento e eficácia da técnica nas sociedades que tinham como base de organização da produção o trabalho escravo e servil não possibilitou o domínio sobre a natureza.

4 O homem é constitutivo de seu meio, é parte da natureza. Ao transformá-la, transforma a si mesmo, mediada pelo trabalho, constituindo-se enquanto ser social. Para sua sobrevivência, necessita dos meios que o ambiente natural dispõe. Entretanto, o sistema do capital ao tornar os meios de existência em mercadoria, bem como o trabalho (a força de trabalho humana) cria uma ruptura entre o homem e a natureza, causando um processo de estranhamento/alienação entre o primeiro e a segunda.

5 Segundo Paulo Netto e Braz (2012), as forças produtivas são o conjunto de elementos que constituem o processo de trabalho. São eles: os meios de trabalho (instrumentos, ferramentas, assim como a terra - meio universal do trabalho) de que se vale o trabalhador; os objetos de trabalho (matéria-prima bruta ou já modificada pelo processo de trabalho) de que incide o trabalho humano; e a força de trabalho (a própria energia humana) que se valendo dos meios de trabalho transforma "os objetos de trabalho em bens úteis à satisfação de necessidades”. (PAULO NETTO; BRAZ, 2012, p. 70).

6 A questão ambiental se manifesta nas mais diversas formas de destruição socioambiental, como o aquecimento global, a poluição industrial nos rios e mares, a intensa produção de lixo com o aumento de produtos mais descartáveis e menos duráveis, desmatamento de florestas entre outras, como já mencionado neste texto anteriormente.

7 De acordo com Caetano, do jornal Brasil de Fato (2019), os campeões em desmatamento e queimadas na Amazônia são o gado e a soja, motivados pela agricultura extensiva do agronegócio. O país registrou o número de 131.327 queimadas florestais até o mês de agosto de 2019. "Só na Amazônia, foram registrados 43.573 focos, segundo o Instituto Nacional de Pesquisas Espaciais (Inpe)". Em 2020, o Brasil registrou um aumento histórico de queimadas no Amazonas nunca visto desde 1998, mesmo o atual presidente eleito Jair Messias Bolsonaro afirmar que "o Brasil é o país que mais preserva” (AMAZONAS..., 2020).

\section{Gessyca Andrea de Lima Baracho \\ gessycabaracho@gmail.com}

Mestranda em Serviço Social pelo Programa de Pós-Graduação em Serviço Social da Universidade Federal de Pernambuco (UFPE)

\section{PPGSS/UFPE}

Av. Prof. Moraes Rego, 1235 - Cidade Universitária

Recife - PE - Brasil

CEP: 50670-901 


\section{Agradecimentos}

Agradeço as/os professoras/es do Programa de Pós-Graduação em Serviço Social (UFPE) pelo compromisso ético-político da formação e defesa intransigente do pensamento crítico em tempos tão difíceis que nos rodeiam.

\section{Agência financiadora}

Não se aplica.

\section{Contribuições das autoras}

Não se aplica.

Aprovação por Comitê de Ética

Não se aplica.

Consentimento para publicação

Consentimento da autora.

Conflito de interesses

Não há conflito de interesses. 